\title{
GEORGIAN DEFENCE POLICY PLANNING MODEL: PUBLIC ADMINISTRATION AND LEGAL ASPECTS
}

\author{
Vephkhvia GRIGALASHVILI, PhD Candidate \\ Faculty of Business Technology, Georgian Technical University, Georgia \\ grigalashviliv@gmail.com
}

\begin{abstract}
This article discusses the main tenets of Georgian national defence policy planning, as well as the institutional mechanisms that are essential for the management and governance of Georgian state defence. The scope of this article references the policy planning documentation at both the national level (via the Parliament or the Cabinet of Ministers, of the Government) and agency level (via the Cabinet of Ministers, or other heads of administrative entities), which pertain to the structure and hierarchy of state institutions as well as the peculiarities of their interaction. Additionally, a discussion of the competencies involved in defence policy planning, with respect to the separation of powers among state institutions, policy planning horizons, characteristics of intermediate stage plans, as well as the methodology involved in defence policy planning. In terms of the overall extent of defence policy planning, the objective of this article is to analyse concepts and factors, which from past observation can be identified as being constructive, or obstructive. Such analysis may help to formulate a more effective way forwards, firstly in terms of recommendations for reshaping the existing national defence policy planning model and ultimately in terms of the realisation of a more effective state governance model.
\end{abstract}

Keywords: Defence Policy Planning, Competencies in Defence Policy Planning, Mechanisms of Defence Policy Planning, Defence Policy Planning Documentation, Horizons of Defence Policy Planning, Methodology of Defence Policy Planning.

\section{Introduction}

The Georgian state's defence management systems, governance systems and defence policy planning systems are better understood in terms of their interrelated whole. Aspects of this interrelated whole include the objectives of the state, the functions and methods of strategic 
planning and management, management structures and personnel within the interrelated parts, as well as resources both financial and material. In addition, it is necessary to consider the processes involved with planning, together with the overall processes associated with the state's defence management and governance.

In view of the above, the effective implementation of Georgian state defence capability (one of the significant parts of Georgian national security) essentially depends upon well-designed defence policy planning. Defence policy planning is considered to be: "a very complex area that influences future defence effectiveness / efficiency and seeks to ensure that a nation has the necessary forces, assets, facilities and capabilities to fulfil its tasks throughout the full spectrum of its missions" (Stojkovic and Dahl, 2007).

It should be noted that the country of Georgia has already implemented reforms in the institutionalisation of national defence (in the areas of management, governance and policy planning). However, with an analysis of the existing model of national defence policy planning, it becomes clear that there is room for improvement in the individual institutional components that comprise the existing model. In particular, in the medium term, it is important to implement certain reforms, so that shortcomings do not lead to a crisis of management at both the national and the agency levels of Georgian state defence.

\section{Methodology}

The methodological approach in this article is based on both a normative and empirical analysis of state defence policy planning in general, and the overall evolution and governance of Georgian national defense, in particular. In other words, a systemic analysis of all the multisegmented parts that relate to Georgian defence policy planning, in terms of the existing situation (empirical), which allows for the identification of institutional flaws in the functioning of the existing system, as well as allows for recommendations to be made about how the overall governance of Georgian national defence could be improved (normative).

The normative and empirical analysis approach in this article pertains to normative acts, policy documents and doctrines (stated principles of government policy in military affairs) which are relevant to the institutionalisation of defence in Georgia, together with an in-depth analysis of national defence policy planning, a functional analysis of government entities participating in this process, and the application of other scientific methods. 


\section{The concept of national defence policy planning}

With reference to the term defence policy planning, and in terms of understanding its precepts, it includes both its ways and means, in other words how the state should act to achieve its goals (methods), and by what means the state intends to achieve its goals (resources) (Tagarev, 2009).

In the context of the concept of defence policy planning from a Georgian perspective, it is important to highlight a difference in the meaning of the words 'policy' and 'politics', which in English are understood mean "the course of actions" (policy) and "the political process" (politics). In Georgian, however, there is only one word '3mmo with the political and leads to the common misconception that defence policy is in the realm of the politicians. Moreover, in terms of means and ends, the term '3mmоతింзs' (politica) is understood narrowly as decisions on the ends, i.e. setting the objectives the Armed Forces must be able to attain (Tagarev, 2009).

Despite the above, in analysing the normative acts of the Georgian state, policy documents and doctrines, it turns out that:

a. The term policy is defined as: "a: Definite course or method of action selected from among alternatives and in light of given conditions to guide and determine present and future decisions; b: a high-level overall plan embracing the general goals and acceptable procedures especially of a governmental body" (Merriam-Webster Dictionary, 2019);

b. The term defence policy is defined as: "a series of guidelines, principles and frameworks that link theory (National Security Policy) to action (Defence Planning, Management and Implementation). Just like an instruction manual, the purpose of defence policy is to ensure things are done in a certain manner in order to attain certain objectives all the while respecting certain rules" (DCAF Security Sector Integrity, 2018);

c. The term defence policy planning is defined as: "consecutive steps towards practical implementation of defence policy, down to actual command and control" (Defence Policy Security Sector Integrity, 2018).

The existence of the two terms the state defence policy planning and the defence planning, in the normative regulations of the Georgian defence organisation, can be considered as a 
hindrance to a homogeneous vision for planning, in the context of the overall national defence policy.

According to the Georgian law on National Security Policy Planning and Coordination, the state's defence policy planning includes the following directives: Detection, identification, assessment and forecasting of military threats; provision of the territorial integrity and sovereignty of the country with armed forces in case of an armed attack; development, preparation and combat readiness of military forces; ensuring the compatibility of the defensive goals with the country's infrastructure and communications; preparation for and carrying out mobilisation measures for the country's economy, central and local authorities, enterprises, organisations and the population; creation of material reserves for defensive purposes; development of a military educational system, as well as military related science and industry; development of international cooperation in security and technical military issues (Law on National Security Policy Planning and Coordination 2015).

According to the Georgian law on Defence Planning, defense planning is part of Georgian defence policy, and an essential element of the overall defence organisation. The law involves targeted measures designed to ensure Georgian national interests and security (including measures that support the country's integration into the North Atlantic Treaty Organisation), and includes the planning of forces, armaments, resources, logistics, management and control, as well as planning for crises and emergencies, and/or state of war and other special situations pertaining to defence planning (Law on Defence Planning 2006).

One point of note concerning the Georgian concept of national defence policy planning is that there is some confusion about the normative scope two terms, namely state defence policy planning and defence planning. According to the normative meaning and scope of these terms, the scope of defence planning is a subset of state defence policy planning. However, with reference to the Georgian law on National Security Policy Planning and Coordination and the Georgian law on Defence Planning, both terms are used synonymously: defence policy planning is a tool for the practical realisation of political and managerial decisions, as well as the ways and means by which the government's goals and plans for the defence of the country are fulfilled. The purpose of state defence policy planning is to achieve: The protection of national interests and the national security of the country; the progressive and planned restructuring of the country's defence capabilities; the effective administrative-state management of state defence; the realisation of good governance 
principles in the defence sector; as well as a proper implementation of the process of integration into the North Atlantic Treaty Organisation (NATO).

The format and hierarchy of conceptual and organisational documentation for defence policy planning at both the national level and the agency level

In general, a defence policy planning document is considered as a normative-political type of document in which the defence policy defined by the government is materialised, and this document represents the action plan for enforcement of this policy (Bucur-Marcu, 2009).

Defence policy planning documents, their format tends to differ considerably from country to country. This is due to the country specific complexities and planning methodologies of defence policy planning, as well as the political culture of individual countries.

Despite the fact that defence policy planning documentation differs considerably from country to country, it is nevertheless possible to categorise and subcategorise these documents. The top level categories include documents with a legal status, which are usually issued by top executive officials and endorsed by the legislature, and documents with executive/organisational status, which are usually issued by the Ministry of Defence and endorsed at executive levels. In terms of subcategories of documents with a legal status, these include: Main policy documents (National Security Strategy, National Defence Strategy, Strategic Concept, Long-term strategic vision), Guidance (Strategic Political Guidance) and Reviews (White Paper on Defence, DefenceStrategic Review). In terms of subcategories of documents with an executive/organisational status, these comprise: Concepts and Strategies (Military Strategy, Procurement Strategy), Plans and Directives (Strategic Capabilities Plan, Defence Planning Directive), Executive policies (Personnel policy, Public Information policy) (Bucur-Marcu, 2009).

Georgian national defence policy planning documentation is regulated by two laws. Firstly, the Georgian law on National Security Policy Planning and Coordination, and secondly the Georgian law of Defence Planning. Together, these two legal acts define the national defence policy planning documentation in terms of its composition and format. Additionally, according to these two laws, conceptual and organisational documents that relate to national defence policy planning are managed at both the national level (where the decision makers are either the Parliament or the Government) and the agency level (where the decision makers are Ministers). 
National defence policy planning documentation at the national level

The set of conceptual documents that are managed at the national level can be ascertained from an analysis of the Georgian law on National Security Policy Planning and Coordination, and the Georgian law of Defence Planning. This analysis identifies the following conceptual document (which have a legal force) titles: the National Security Concept (which is approved by the Parliament), the Threat Assessment Document, the National Defence Staretgy (which are approved by the Cabinet of Ministers of the Government), as well as the National Military Starategy operating in the transition period and the Defence-Strategic Review (which are approved by the Cabinet of Ministers of the Government), which will be terminated after the National Defence Staretgy development and entry into force.

With reference to the conceptual document entitled National Security Concept, this document is fundamental to both Georgian national security policy and to the organisation of Georgian state defence. Moreover, this document applies to multiple sectors and all national defence policy planning documents must comply with its directives. It defines the national values and interests; establishes a vision for the country's safe development; determines the threats, risks and challenges facing the state; as well as establishes the main objectives of national security policy (National Security Concept 2011).

In terms of how closely Georgia's National Security Concept aligns with the standard pattern, it is clear from the above that it aligns very closely, and one can also quote MacFarlane's assessment as follows: "Georgia's National Security Concept follows the standard pattern closely. A description of the country's security environment is followed by a discussion of national values and interests. It then turns to threats, challenges and opportunities, before concluding with a list of priorities" (MacFarlane, 2012). Alignment of the National Security Concept document with the standard pattern is a positive, however weaknesses have been identified, such as: An overemphasis on political positions/statements, weak strategic analysis, neglecting important risks, a failure to understand threats and promoting unrealistic expectations. With respect to strengths, we can again quote MacFarlane: "One strength of Georgia's National Security Concept is the clear recognition that security is not only about military and diplomatic affairs (high politics). The Concept embeds discussion of military and conventional strategic threats in a wider context of economic development and interdependence, energy vulnerability and modes of domestic governance" (MacFarlane, 2012). 
Military security is an important objective and function of the national defence organisation, the main purpose of which is to prevent, localise and neutralise military threats. Consequently, the Threat Assessment Document of Georgia has a special institutional importance in the planning of national defence policy. The composition of the Threat Assessment Document is regulated by the Georgian law on National Security Policy Planning and Coordination, and must also comply with the directives of the National Security Concept. One of the directives obliges the government to review the strategic environment with a long-term horizon, and to determine: military, foreign policy, domestic policy, transnational, social and economic, natural and technogenic threats and challenges that pose a significant danger to the national security of the country.

Before legislative amendments in 2018, in the field of defence at the national level, there were a set of conceptual documents (the National Defence Strategy, the Defence Strategy Review and other security (including defence) strategies) collectively called: National Security Strategies, which (the National Defence Strategy, the Defence Strategy Review and other strategies related to national defence) have since been consolidated and amended into one set of documentation known as the National Defence Strategy. This documentation is of an executive nature (as it was prior to 2018) and makes recommendations about how national security strategies should be implemented. It also contains action plans and timetables, which determines the time, means and responsible agencies for the execution of specific tasks. The executive nature of above mentioned strategies is in contrast to other conceptual documents at the national level, such as the National Security Concept and the Threat Assessment Document, which are about political positions and declarations.

Prior to the legislative amendments of 2018, as mentioned above, there were actually three documents which comprised the group of the National Security Strategies for defence policy planning. These documents were the National Military Strategy, the Defence Strategic Review and so called "Other Security Strategies" related to national defence:

The National Military Strategy document constituted the country's primary militarypolitical document, which specifically defined the multi-year national military objectives and requirements, general ways of their implementation, structure and future vision. Additionally, the document contained a definition of the abilities required of the Armed Forces, such that they could fulfil their missions effectively (Military Strategy of Georgia 2014); 
The Defence Strategy Review document determined the basic areas of development vis-àvis the Ministry of Defence and the Armed Forces, the future structure (for a definite period of time) of the armed forces, as well as the means and mechanisms for improving the compatibility of the Armed Forces of Georgia, with the North Atlantic Treaty Organisation (NATO) (Security Defence Review of Georgia 2017)

The reason for transitioning from the National Security Strategies (the National Military Strategy, the Defence Strategy Review and so called "Other Security Strategies" related to national defence) model, to the National Defence Strategy model, and for the legislative amendments of 2018, was Georgia's decision to implement a new paradigm known as Total Defence that compromises the five pillars of: Psychological Defense, Social Defence, Economic Defence, Civil Defence and Military Defence. This necessitated the replacement of the above named strategic documents, as well as consolidating the principles of the Total Defence paradigm into the new National Defence Strategy. The essence of the new strategy is the total mobilisation of both military and civilian resources, so as to maximise Georgia's national defence capability, given the existing threats and limited resources.

The reformed National Defence Strategy model came into force in 2018, with amendments to the Georgian law on Defence Planning. In summary, the directives of the law are as follows: Review and evaluate the threats and challenges in the field of defence; determine the objectives of the country's defence policy and international cooperation, determine national military objectives and tasks, as well as the ways, principles and means of their fulfilment; assess the country's defence capabilities, assess the requirements of the Defence Forces, establish the future development vision and determine the future structure of the Defence Forces, determine the strategic objectives and principles related to the organisation of the defence of the country; define the defence tasks of the state agencies in accordance with the relevant areas; define civil involvement in national defence; establish the framework of the Georgian Defence Force resources for a specific period (Law on Defence Planning 2006). However, it is reasonable to note that the National Military Strategy, the Defense Strategic Review Document, and the "Other Security Strategies" have been remaining the legal power before the National Defense Strategy is elaborated.

One important innovation related to the 2018 amendments to the Georgian law on Defence Planning is a new organisational document entitled National Defence Preparedness Plan, which is now part of state defence policy planning at the national level. The document is closely related to 
the National Defence Strategy. The way that it works is that through the national level conceptual documents, agencies are tasked with implementing certain aspects of the national defence strategy. It then becomes the responsibility of these agencies to develop an action plan, which is then appended to the National Defence Preparedness Plan. It should be noted that multiple different agencies may be tasked in this way, and each will make their own individual contribution (Action Plan) to the National Defence Preparedness Plan (Law on Defence Planning 2006). However, the Agency's Action Plan status in the hierarchy of defense policy planning documents is legally uncertain.

Figure 1: National defence policy planning documentation at the national level

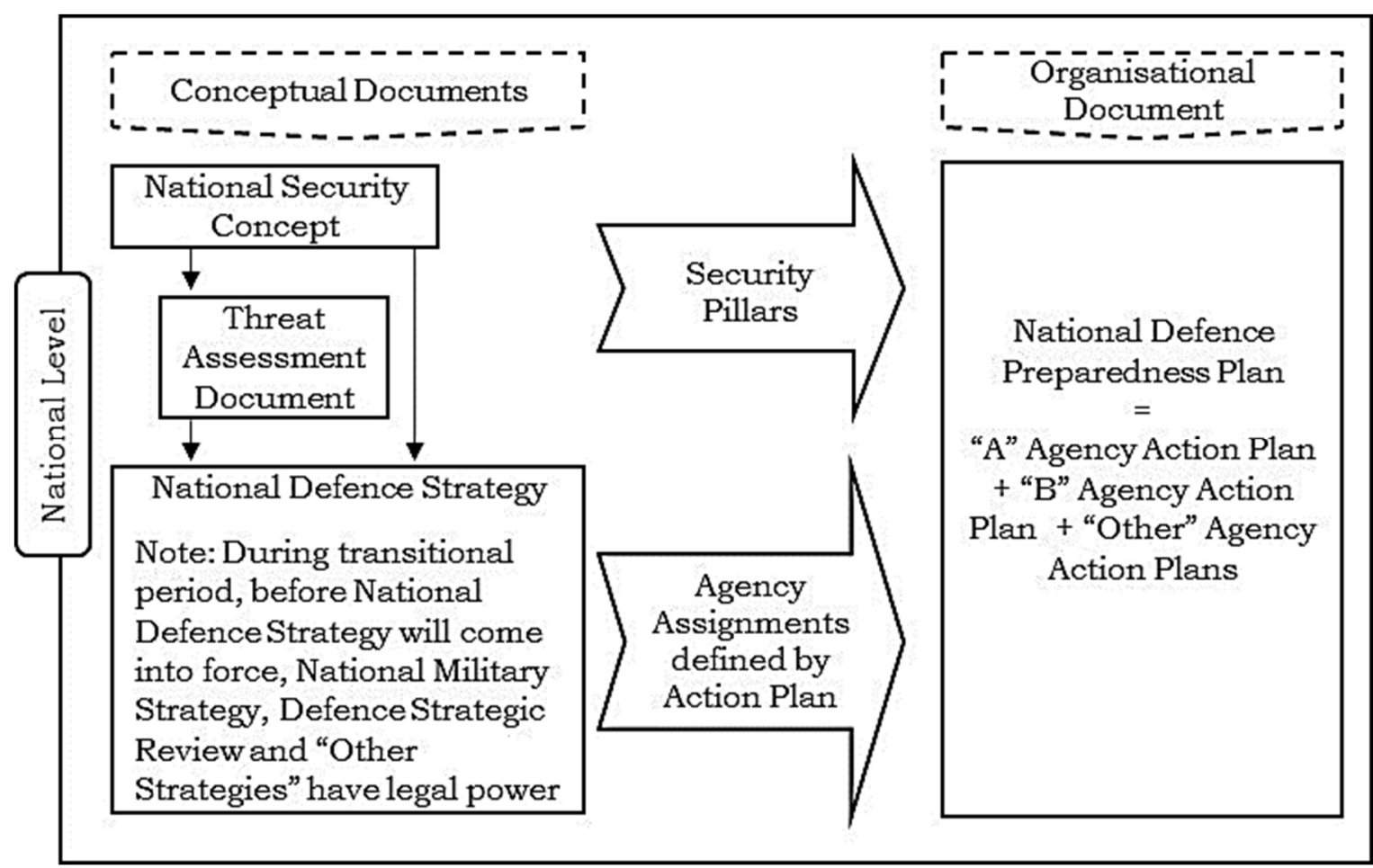

Source: Grigalashvili (2018a)

National defence policy planning documentation at the agency level

In terms of the overall national defence policy planning process in Georgia, there are a set of conceptual documents at both the national level, and at the agency level. Furthermore, 
conceptual documents at the agency level are derived from conceptual and organisational documents at the national level.

The purpose of the conceptual documentation at the agency level is to define how the objectives and goals set at the national level are to be implemented and realised in actuality. At the same time, given that many entities are likely be involved in the implementation and realisation of state defence, the documentation at the agency level must also provide a framework for their management. Moreover, this will be the case for all subjects addressed by the conceptual documentation at the agency level.

Prior to the 2018 legislative reforms, there were two legislative acts that applied to planning at the agency level. These two legislative acts were the Georgian law on Defence Planning and the Georgian law on National Security Policy Planning and Coordination. Unfortunately, these two legislative acts applied different systems for agency level planning, which resulted in conflicts and confusion for the policy community within the executive authorities involved in the defence policy process. Moreover, there was little correlation between the two planning systems, and it was often unclear as to which planning system should apply, in a particular case. Consequently, this led to shortcomings in the planning process at the agency level.

For the purposes of elucidating the pre-2018 and post-2018 legislative reforms that pertain to agency level planning, and thus explain their transformation/development, it is useful to list the agency level documentation requirements in the Georgian law on Defence Planning, before those reforms. The prior list of documentation was as follows (with a final note on the budget calculation):

a. The Defence Planning Guidance, which was based on documents at national level, reflected the priority objectives and planned measures for the state's defence by the Armed Forces of the Ministry of Defence of Georgia over a long-term timeframe;

b. The Main Programmes of military development, which was based on the Defence Planning Guidance, and detailed all of the planned events over a long-term timeframe, and was also aimed at the modernisation of the Georgian Armed Forces, equipping the Armed Forces, training, maintenance of subdivisions, logistics, upkeep and improvement of the reserve infrastructure, as well as ensuring implementation of cooperation plans with NATO;

c. The drawing up of the Annual Programmes represented the final stage of defence planning and the annual steps of major programmes for military development. Finally, as a result 
of the review and summation of programmes by their annual cost basis, a defence budget was drawn up, which was then reflected in the State Budget (Law on Defence Planning 2006).

It should also be noted, with reference to the above, that the three key sets of documentation (the Defence Planning Guidance, the Main Programmes of Military Development and the Annual Programmes) formed a strict hierarchy. In other words, the Defence Planning Guidance fed into the Main Programmes, which fed into the Annual Programmes. There was also an additional document called the Defence Planning Regulation. This document did not belong to other groups, such as conceptual or organisational documents, and its main purpose was for the organisational provision of planning at the agency level, such as the procedures, responsible institutions, terms of reference and deadlines.

To expand upon an earlier point about the two legislative acts that applied to agency level planning, before the reforms of 2018, it is useful to list some of the legislative aspects of the then Georgian law on National Security Policy Planning and Coordination. This law applied to various aspects of planning at the agency level, such as standardised documentation formats/structure intended for multi-agency use, general frameworks and a wide range of regulatory documents. It also defined a relatively flat (vs hierarchical) organisational structure for documentation (in terms of the interdependence of documents).

In terms of the conceptual documents that were defined by the then Georgian law on National Security Policy Planning and Coordination, they comprised:

a. The Agency Concept. The Agency Concept document set out the vision, values, approach, ideas, intentions and general principles (all of which were to adhere to the appropriate circumstances and requirements) of the relevant agencies, in the sphere of national defence. The concept was also required to include the vision of the head of the relevant agency about the specific objectives, tasks and activities, as well as how these were to be carried out;

b. The Agency Strategy. The Agency Strategy document was based on documents at the national level pertaining to objectives in the area of state defence, and its purpose was to define how these goals and objectives would be carried out and achieved. Also, it was necessary for the documentation to contain a detailed analysis of documents at the national level that pertained to the area of state defence and identify any problems/issues with them, as well as to propose ways to resolve these issues/problems. The strategy document was also required to include an action 
plan and timetable for determining the time, means and the structural units responsible for the execution of specific tasks;

c. The Doctrine. The Doctrine document detailed how the resources of a particular agency were to be effectively used to carry out specific task(s) in the area of state defence;

d. The Programme. The programme determines special measures to be taken depending on the areas and/or fields that pertain to military defence, in this law and the mechanisms for the implementation of those measures. The programme does not identify the plans for the implementation of the above measures (Law on National Security Policy Planning and Coordination 2015).

The legislative reforms of 2018 radically and fundamentally changed the composition, format and hierarchy of both the conceptual documentation and organisational documentation at the agency level, for national defence policy planning. Consequently, two groups of documents were defined and organised in a hierarchical manner as follows:

a.The first and top-level group of conceptual documentation determines the vision, values, intentions and principles of the relevant agency. It also determines the goals and objectives of this relevant agency, which specifically pertain to the state defence area, as well as other objectives and issues it might have;

b. The second-level group of conceptual documentation (subordinate to the top-level group) deals with the executive strategy, in other words how the goals and objectives of the top-level strategy are transposed into a set of strategic projects and tasks. The relevant agency is then required to detail the timeframe, ways, means and resources that are necessary to accomplish these strategic projects and tasks, within its authority, and to identify the responsible structural unit(s), as well. Additionally, the relevant agency may also provide an action plan and timetable (Law on Defence Planning 2006).

In addition to the above, with respect to the legislative reforms of 2018 , there is also a set of organisational documentation at the agency level. These are known as the executive documents, and comprise detailed information about how strategic projects and tasks are to be carried out, by the relevant agency. This documentation is based on conceptual documentation at the agency level, and/or documents at the national level. 
Figure 2: National defence policy planning documentation at the agency level

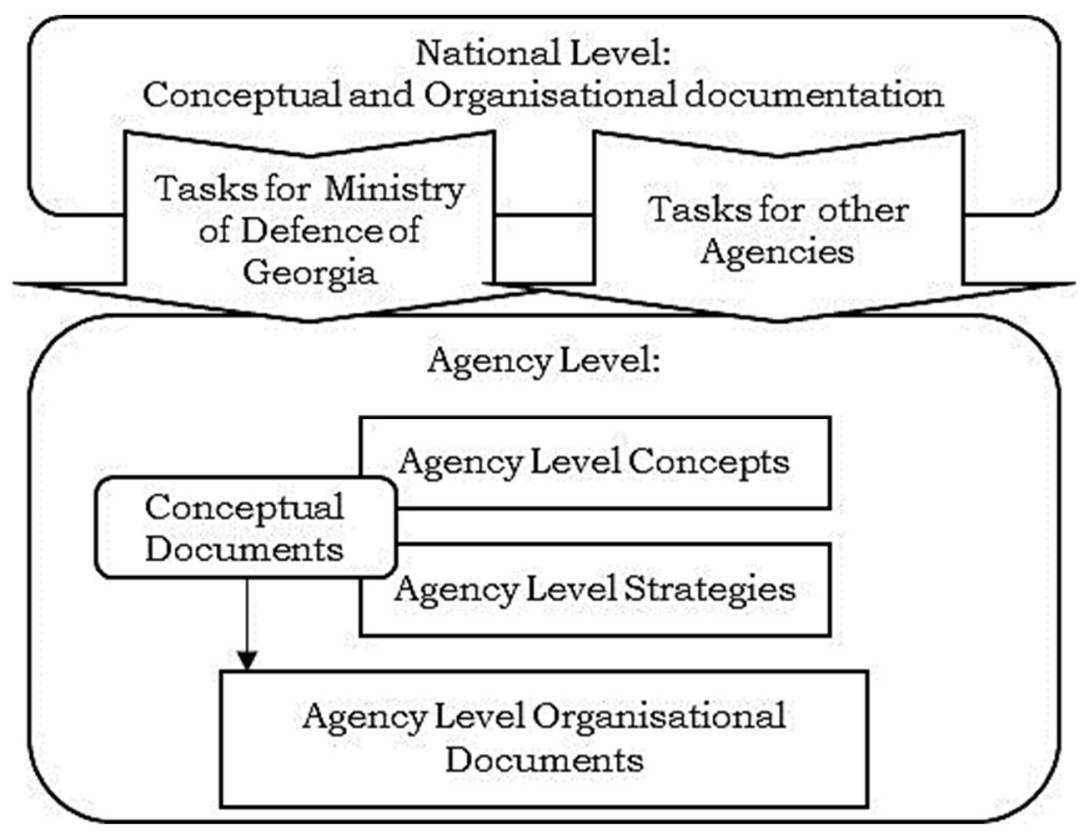

Source: Grigalashvili (2018b)

\section{Legal competence and authority in national defence policy planning}

In general, national defence policy planning is understood to be the product of inter-agency activities, in various formats, carried out by state agencies. This planning must be carried out according to the principles of legality, the protection and respect of human rights and fundamental freedoms. The inter-agency activities should also be part of a unified governmental approach which involves transparency, as well as consistency, advance planning and civic engagement.

The Constitution of Georgia assigns the governance of state defence to the highest state bodies. Accordingly, the legal competence/authority of determining national defence policy is split between the Parliament of Georgia and the executive authorities of the country, the highest governing body of which is the Georgian Government (the Cabinet of Minister as the collegial executive body and Ministries as executive organs). As for the President of Georgia, according to the existing parliamentary governance model, the executive power concerned with national defence policy planning has been disassociated with the institution of the President (Constitution 1995). 
Again, according to the Constitution, the Parliament of Georgia makes the primary decisions on the objectives of both the state's foreign and domestic defence policy. However, the Government has the exclusive authority for formulating state defence policy, so that it can be submitted to the Parliament for consideration. Additionally, the Government of Georgia is responsible for formulating the National Security Concept, which represents the primary political statement in the realm of state defence planning. The Government must submit a draft version of the National Security Concept to the Parliament of Georgia, for approval.

According to the Rules of Procedure of the Parliament of Georgia, there are certain restrictions that relate specifically to the National Security Concept. Specifically, in contrast to other areas of legislation, the Parliament of Georgia does not have the legislative competence/authority to amend the National Security Concept. In short, no amendment can be made to the document without prior consultation with and the agreement of the Government of Georgia. In the event that the Government of Georgia submits a draft version of the National Security Concept to the Parliament of Georgia for consideration, and no consensus can be achieved because of controversial provisions in the document, then the Parliament of Georgia is authorised to return the document to the Government of Georgia, with remarks. In light of these remarks, the Government of Georgia may resubmit a compromise a draft version of the National Security Concept to the Parliament of Georgia for their reconsideration (Rules of Procedure of the Parliament 2018).

As previously mentioned, the Parliament of Georgia is assigned the right to determine the primary objectives of national defence policy, specifically in terms of approving a draft version of the National Security Concept. Additionally, at the same time as approving this document, the Parliament of Georgia delegates the responsibility for the formulation (detailed policy) and implementation of national defence policy to the Government of Georgia. This works, under supervision of the Georgian National Security Council, primarily through the Standing InterAgency Commission (which came into being as a result of the 2018 legislative reforms) who manage the creation and refinement of both conceptual and organisational documentation at the national level, in the field of national defence. This Commission creates draft documents for the approval of the Cabinet of Ministers, of the Government, and the approval of these draft versions of national defence policy planning documents (the Threat Assessment Document, the National Defence Strategy and the National Preparedness Plan) confers legal status to them. 
In terms of the legal competence/authority for the defence policy planning process and documentation at the agency level, this legal competence/authority is assigned to the head of the relevant agency (mostly to relevant Ministry).

The Standing Inter-Agency Commission, as previously mentioned, was brought into being in the 2018 legislative reforms. There were predecessor commissions, but a key change with the new Standing Inter-Agency Commission is that the Deputy Minister of Defence now heads the commission. This change means that the Ministry of Defence has gained a more prominent role in the overall coordination of national defence policy planning at the national level.

\section{National defence policy planning process and horizons}

National defence policy planning is a complex, multi-stage and iterative process. Defence planning is also an interdisciplinary process that comprises many various activities. Activities are mutually dependent and precise coordination is paramount. However, there is no consensus about the number of stages, or even about the institutional framework that should apply.

With reference to the multi-stage defence policy planning process in the paragraph above, and in terms of a consensus approach, it is possible to identify differences even between NATO documents. For example, in the NATO Handbook on Long-Term Defence Planning, the eight main stages of the process outlined in this document are as follows: Political guidance analysis; Environmental assessment; Mission analysis, Planning situations development; Capability requirements determinationl Capability assessment; Options development and solution selection. In contrast, on the NATO website detailing the NATO Defence Planning Stages, there is an alternate approach: Establish political guidance; Determine requirements; Apportion requirements and set targets; Facilitate implementation; Review results.

The defence policy planning process in Georgia is based on disciplined approaches to the creation of force structure and force development plans, within an iterative framework. This overall approach is broken down into multiple stages, as follows: Determining the primary objectives of defence policy in terms of national security values and interests, as well as the domestic and external threats to the country; defining the goals, tasks and ambitions of national defence and detailing the appropriate strategies for their achievement; design of plausible scenarios; decomposition of the scenarios into goals, and then from these goals formulate a set of tasks, and ensure that there is no duplication of these tasks; determining the resources required to 
carry out the set of tasks; considering the tasks and scenarios, detail the structure of the Defence Forces and planning for those forces; operational planning.

The Georgian law on Defence Planning requires that state defence planning is carried out over short-term timescales (up to two years), over medium-term timescales (up to five years) and over long-term timescales (five and more years). However, the law does not specify any scope for state defence planning over short, medium or long-term timescales. Nevertheless, based on scientific literature and analyzing defence policy planning documents, the institutional characteristics of each period of planning can be determined.

Long-term defence planning is a specific planning discipline that is related to the relatively distant future. It involves a process that investigates possible future operating environments and develops a force structure development plan to best adapt the defence organisation to those environments given a host of constraints (RTO Technical Report 69, 2003). The purpose of defence planning, particularly long-term defence planning, is to define the means, including the future force structure (Tagarev, 2006), that would allow defence institutions to deal effectively with likely future challenges. Long-term planning is often referred to as strategic planning, and strategic planning is synonymously used in defence policy planning (Stojkovic and Dahl, 2007).

Long-term defence planning also involves a continuous analysis of the strategic environment. In particular, it is important for defence planners to identify changes or trends in the strategic environment that pertain to threats, potential risks or challenges. It is also important to consider changes or trends in the role of military-political alliances, as well as in the defence strategies of neighbouring countries. For example, a change in the defence strategy of a neighbour may be indicative of an increasing regional threat, which might warrant a reconsideration of one's own defence strategy. Additionally, defence planners must analyse the role of new technologies vis-à-vis the capabilities of the Armed Forces, and based on this analysis, determine the priorities of the country's defence policy, as well as the future structure of the Defence Forces and planning for those forces.

Therefore, the general purpose of long-term defense planning is to (re)consider the mission of the defence and to establish realistic long term goals and objectives consistent with that mission, as well as to define strategies for their fulfillment (Stojkovic and Dahl, 2007).

In addition to the above, the effective management of defence involves a consideration of capability, which is somewhat of an abstract concept. In ordinary usage, the term donates the 
capacity to be or do or affect something. The planning community therefore needs a capability model, or framework, that presents all capability components in a commonly understood manner. Initially, we can first look to the definitions that defence planners give to the word capability in various countries. For example, Australian defence planners define capability as: "The power to achieve a desired operational effect in a nominated environment, within a specified time, and to sustain that effect for a designated period" In the United States, the Homeland Security community uses the following definition: "A capability provides a means to perform one or more critical task(s) under specified conditions and to specific performance standards" (Tagarev, 2006).

In terms of capability models, one can look to the Canadian model known by the acronym PRICIE (P - Personnel; R - Research and Development / Operations Research; I - Infrastructure and Organisation; C - Concept, Doctrine, Collective Training; I - IT infrastructure; E - Equipment, Supplies and Services). In the United States, their capability model is known by the acronym DOTMLP (D - Doctrine; O - Organisation; T - Training and Education; M - Material; L Leadership; P - People). NATO uses the following acronym DOTMLPFI (D - Doctrine; O Organisation; T - Training; M - Material; L - Leadership; P - Personnel; F - Facilities; I Interoperability) (Tagarev, 2006). Finally, as for Georgia, in accordance with the Defence Strategic Review of 2017-2020, the defence capabilities model is known by the acronym DOTLMPF (D Doctrine; O - Organisation; T - Training; L - Leadership; M - Materiel; P - Personnel; F Facilities).

Despite the diverse approach to capability models, as listed above, all of them share a common objective, namely the ability of a country (or alliance), both qualitatively and quantitatively, to achieve measurable outcomes vis-à-vis their defence goals, according to a specified set of circumstances and to specific performance standards.

It is important to note that the design of Georgian national defence policy planning documentation (adopted by the Cabinets of Ministers of the Government) at the national level corresponds to the requirements of long-term defence policy planning. For example, the Threat Assessment Document covers a multi-year timeframe, and outlines the existing strategic environment, as well as identifies the threats and challenges facing the country. Based on this, the National Military Strategy of Georgia defines the military objectives and tasks (as well as the principles etc.) that pertain to national security. However, in contrast to the above mentioned documentation at the national level, the National Security Concept does not contain any long-term 
defence planning timeframes, or only refers to periods of time in an abstract way. Therefore, it can be argued that this is a deficiency in the overall national defence planning model of Georgia.

In a practical sense, the main purpose of mid-term planning is to guarantee that the actual defence management activities, e.g., reorganisation, recruitment, procurement, training, spending money, etc., serve to achieve defence policy objectives and to build the respective future force. Policy makers (at the national and agency levels) typically develop multiple mid-term plans / programmes which provides for the development, or at least for a qualitative change, of force capabilities (Tagarev, 2006). The process of creating these programmes is therefore called programming and the ongoing process as - programmatic planning. For example, the interim planning of national defence policy in Georgia is served by the documents at the national level, such as the National Military Strategy and the Defence Strategic Review 2017-2020, as well as the White Book at the agency level of 2017-2020, and the Defence Planning Guide 2018-2021.

Short-term plans are an integral part of programmes, and programmes are a set of mid-term plans with varying start dates, timeframes and in some cases dependencies. Budgeting is based on programmes, but on an annual basis, and is carried out according to the Georgian law on the Budget Code of Georgia. According to the requirements of this law, programmes must have a well-defined set of goals/outcomes for measures that are funded on an annual basis. This then feeds into the annual budget, according to the Georgian law on the Annual Budget, which lists the programmes to be funded for a particular year, and the total GEL (Georgian Lari) amount allocated. The measures to be carried out are then assigned to the appropriate budgetary institutions, which are then responsible for their implementation.

One of the characteristics of long-term defence planning is that in planning for hypothetical scenarios into the future, over time, geopolitical or other factors can make such eventualities more, or less, likely. Consequently, programmatic planning involves adapting the directions of mediumterm and short-term planning, such that they are more closely aligned with the evolving reality of the current situation. Moreover, decision makers and planners must, on an ongoing basis, ensure that the Armed Forces are structured in such a way as to maximise their effectiveness according to anticipated financial resources, technological developments, demographics and strategic environment, as well as other significant variables/constraints. So, it is clear that unforeseen events, or unexpected changes in the strategic environment can impact upon every level of defence planning (long-term, mid-term and short-term), which in many cases invalidates existing medium- 
term and short-term planning. As a result, a regular re-evaluation of medium-term defence policy planning is required, in order to effectively respond to these unforeseen events and changes. This can lead to new programming, or in other words the development of new programmes, on an annual or biannual basis, which in turn results in the updating of short-term plans (Tagarev, 2006).

A programme, in the context of defence policy planning, is a comprehensive plan for the purpose of developing certain capabilities that a defence organisation can possess and implement, if and when necessary (Tagarev, 2006). These plans detail how a capability is to be achieved, with new and/or existing resources, how the capability will be maintained and the specification/characteristics of the product (outcome of the programme). Moreover, one major aspect of developing a programme is to support the decision-making process in terms of the procurement, or allocation, of resources for the product, as well as to ensure a results-oriented policy or plan that maximises capabilities. Besides the above, programmes help to reconcile the policy objectives with the budget. Furthermore, they are the means by which the future vision of defence planning is transformed into short-term plans, which results in the reorientation and direction of force structure. Finally, a programme provides transparency in terms of the budget, so that the financing is more understandable to the managing bodies, as well as to other interested parties (Tagarev, 2006).

In defence planning policy, so as to support the full realisation of products (outcomes of programmes), it is recommended that planners adhere to few key principles in the design of programme structure. Firstly, programmes should detail, in as clear a way as possible, the relationship between spending and the final product i.e. capabilities. The next key principle is that it should be comprehensive: No monies may be spent outside the programme and no work may be undertaken on anything outside the programme; it shall account for all monies that will be spent on defence; final decisions need to be made about all programmes at the same time, with objective analysis of the trade-offs. Another key principle is that it should provide for a realistic distribution of responsibilities among programme managers. The final key principle is that it should be manageable, in other words that the programme structure and procedures should provide opportunities to objectively assess and search for trade-offs in resource allocation (Tagarev, 2006). 


\section{Approaches to national defence policy planning - methodology}

Institutional regulation of the methodology associated with defence policy planning is absent in Georgian national legislation, policy documentation and doctrines. However, an analysis of the state's planning policy documentation, both at the national level and at the agency level (as well as an analysis of the planning process), reveals that the general approaches (methodology) to defence policy planning, as listed in the NATO Handbook on Long-Term Defence Planning, are indeed an integral part of defence policy planning in Georgia:

1. Focus: The planning process:

a. Top-down planning.

1. "This is a "strategy to tasks" approach to planning. The process begins with the specification of top-level policy, interests and objectives. Strategies are developed that support overall policy and objectives. This approach is then cascaded down through lower levels" (RTO Technical Report 69, 2003). "The hierarchy continues through roles and tasks to concepts and force elements. The process examines capability requirements from a conceptual basis linked through the framework, to national goals" (Stojkovic and Dahl, 2007).

It is noteworthy, that the so-called 'bottom-up' approach is also actively used in national defence policy planning, during which: "the focus is on improvement of existing defence capabilities and related weapons systems - improvement aimed above all at meeting the requirements of current operations and operational plans" (Henry et al. 1995);

b. Resource-constrained planning.

"The objective of this planning approach is to provide a viable capability that is sustainable within the provided budget. No effort is made to investigate force structure options that are more expensive, regardless of the potential performance jumps such budget violations might incur" (RTO Technical Report 69, 2003). This approach is also called Budget-Based Planning that attempts to maximise defence capability for the funds available;

2. Focus: Degree of technology optimism versus historically proven facts:

a. Technology optimism.

"A key development goal is to obtain operational and strategic superiority through technology. Force structure development is carried out so as to fully exploit technology" (RTO Technical Report 69, 2003). This approach is also called Technology-Driven Solutions;

b. Risk avoidance. 
"Proven concepts and structures are extrapolated and extended. This conservative approach continues current ways as long as they are deemed successful. Defence development adheres to current strategy, doctrine, tactics and structure and incorporates new technology, when proven available and appropriate. This method tries to maintain the status quo in defence capability in a relative sense" (RTO Technical Report 69, 2003);

c. Incremental planning.

"This approach seeks in an evolutionary manner to improve the existing inventory of defence capabilities. Existing capabilities form the foundation of new capabilities. The approach focuses on the assured enhancement of current capabilities and, as such, tends to concentrate on the near-term developments and options. Incremental planning is an instance of a risk avoidance approach" (RTO Technical Report 69, 2003);

d. Historical extension.

"Similar to incremental planning, the basic premise is that what worked in the past will work again in the future. Analysis of future operational effectiveness of various options is based on a historical analysis. Past operations are evaluated to identify the factors that most significantly contributed to success and/or failure. The future force structure is then designed to take greatest advantage of the positive factors while avoiding the negative ones" (RTO Technical Report 69, 2003);

3. Focus: Functions or concrete scenarios as the driver for measuring performance:

a. Capability-based planning.

"This method involves a functional analysis of expected future operations. The future operations themselves do not enter the performance evaluations. The outcome of such planning is not concrete weapons systems and manning levels, but a description of the tasks force structure units should be able to perform expressed in capability terms. Once the capability inventory is defined, the most cost-effective and efficient physical force unit options to implement these capabilities are derived" (RTO Technical Report 69, 2003);

b. Scenario-based planning.

"This approach utilises a representative set of hypothetical situations for the employment of Defence Forces. The situations are specified in terms of environmental and operational parameters. Defence capability requirements are determined from assessments of the ability to achieve formulated mission objectives" (RTO Technical Report 69, 2003); 
c. Threat-based planning.

"The threat-based approach involves identifying potential adversaries and evaluating their capabilities. Capability or system requirements are based on the criterion of outperforming the opposition. Quantitative and qualitative solutions are explored". (RTO Technical Report 69, 2003).

\section{Conclusion}

Based on the analysis, we can conclude that planning of Georgian national defense policy is a multidimensional system process (Fig.3). The national defence planning system is based on the following values: a) sovereignty and territorial integrity; b) freedom; c) democracy and supremacy of law; d) safety; e) well-being; f) peace, and the national defence planning and its coordination principles are as follows: a) legality; b) exclusive protection and respect of human rights and fundamental freedoms; d) unified government approach; d) continuity; e) planning; f) publicity and civic engagement.

Figure 3: National defence policy planning system
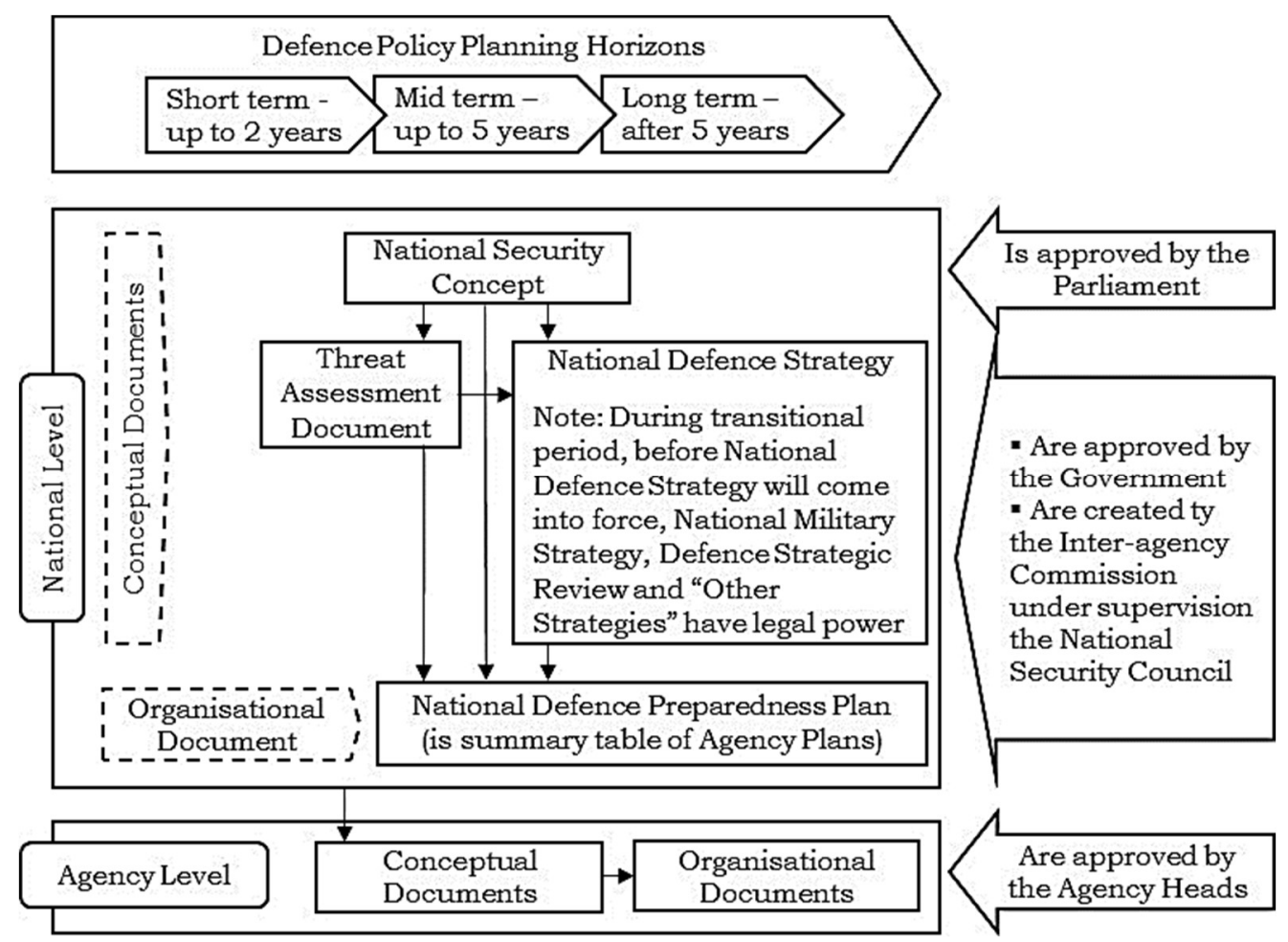

Source: Grigalashvili (2018a) 
In the defence planning process the executive branch - the Government of Georgia (The Cabinet of Minister's), has the leading role, respectively, powers of the Parliament are limited proportionally, which is somewhat incompatible with parliamentary governance model, as it hinders effective parliamentary control, it also creates a danger of breaking the governmental balance between legislative and executive branches.

Consequently, it is advisable to implement legislative amendments which will, at least, allow the Parliament to initiate amendments, based on prior acceptance with the executive branch, to the National Security Concept.

Analysis of the defence policy planning system shows that, despite the carried out reforms, there are still institutional deficiencies in the defense policy planning mechanism that need further development.

This research has shown that a methodology of defence policy planning is not institutionalised at both the national and the agency level, which makes it more difficult to introduce uniform approaches in the planning process.

Consequently, it is advisable that the government adopt a normative document (for example, considering NATO's experience), which will define general methodological approaches to planning defence policy.

Compared to the defence policy planning at the national level, the planning process at the agency level still requires further institutional improvement, despite prior reforms. Specifically, the uniform rule of planning is not normally defined, at the state level, according to which the institutions involved in the national defense planning process will be guided. Also, the names of the departmental documents and their regulation sphere are not defined by the name, which negatively affects the standard procedures of the process.

Therefore, it is recommended that the government adopt a normative document, forming the format of the uniform planning model and regulating the planning process, it is also recommended that it systematically integrate average and short-term planning documents format, as well as assessment and monitoring mechanisms.

\section{Acknowledgment}

The author would like to thank Dr. Genadi Iashvili and Dr. Shota Dogonadze, professors at Georgian Technical University, for their assistance and guidance in the research process. 
This work is supported by Shota Rustaveli National Scientific Foundation (SRNSF) (Grant No: PhD-F-17-123, Project title: Problems of Georgia`s national defence management and ways of solving them).

\section{References}

1. BUCUR-MARCU, H. (ed.) (2009) Essentials of Defence Institution Building, LVAk/DCAF: Vienna and Geneva, pp.7-36.

2. BUKUR-MARKU. et al. (eds.) (2009), Defence Management: An Introduction, Geneva: Procon Ltd, pp.47.

3. CONSTITUTION OF GEORGIA 1995 (Chapter 2,3,4). Tbilisi: Legislative Herald of Georgia

4. DCAF SECURITY SECTOR INTEGRITY (2018). [Online] DCAF Security Sector Integrity. Available from: https://securitysectorintegrity.com/defencemanagement/defence-policy [Accessed 23/05.19]

5. DEFENCE POLICY - SECURITY SECTOR INTEGRITY (2018). [Online] Defence Policy - Security Sector Integrity. Available from: https://security sectorintegrity.com/defence-management/defence-policy [Accessed 23/05/19 ]

6. GEORGIAN LAW ON DEFENCE PLANNING 2006 (Articles: 2-11). Tbilisi: Legislative Herald of Georgia.

7. GEORGIAN LAW ON NATIONAL SECURITY POLICY PLANNING AND COORDINATION 2015 (Chapter 1-3). Tbilisi: Legislative Herald of Georgia.

8. Grigalashvili V. (2018a). Format and Hierarchy of National Defense Planning Documents. Authority and Society (4)48 2018, pp. 5-9.

9. Grigalashvili V. (2018b), Policy Planning as Segment of National Georgian Defence Management. Science Review 2(9), February, 2018, pp. 124-127.

10. HENRY, C. et al. (1995), The Art of Strategy and Force Planning, in Strategy and Force Planning, Newport, R.I: Naval War College Press, Vol. 48: No. 2, pp.17-33.

11. MACFARLANE, S.N. (2012) Georgia: National Security Concept versus National Security, Tbilisi: Center for Social Sciences, pp.6-36. 
12. MERRIAM-WEBSTER DICTIONARY (2019). [Online] Merriam-Webster Dictionary. Available from: http://www.webster-dictionary.org/definition/defence $\% 20$ policy [Accessed 23/05/19]

13. NATIONAL MILITARY STRATEGY OF GEORGIA 2014 (pp.2-15). Tbilisi: Legislative Herald of Georgia.

14. NATIONAL SECURITY CONCEPT OF GEORGIA 2011 (pp.2-24). Tbilisi: Legislative Herald of Georgia.

15. RTO TECHNICAL REPORT 69. (2003) RTO Technical Report 69 Handbook on Long Term Defence Planning. North Atlantic Treaty Organisation Research And Technology Organisation, pp.3-12.

16. RULES OF PROCEDURE OF THE PARLIAMENT OF GEORGIA 2018 (Articles 156234). Tbilisi: Legislative Herald of Georgia.

17. SECURITY DEFENCE REVIEW OF GEORGIA 2017 (pp.2-14). Tbilisi: Legislative Herald of Georgia.

18. STOJKOVIC, D. and DAHL, B. (2007), Methodology for long term defence planning. Oslo: Norwegian Defence Research Establishment (FFI), pp.7-12.

19. TAGAREV, T. (2006) Introduction to Program-Based Defence Recourse Management. Connections: The Quarterlly Journal, No.5, pp.48-82.

20. TAGAREV, T. (2009), Defence Planning Core Processes in defence Management. In Bucur-Marcu, H., Fluri, P., Tagarev, T., (Eds.) (2009), Defence Management: An Introduction, Geneva: Procon Ltd, pp. 45-75. 